\title{
Provision of disability adaptations to the home: analysis of household survey data
}

Article

Accepted Version

Ewart, I. J. and Harty, C. (2015) Provision of disability adaptations to the home: analysis of household survey data. Housing Studies, 30 (6). pp. 901-924. ISSN 0267-3037 doi: https://doi.org/10.1080/02673037.2014.991379 Available at https://centaur.reading.ac.uk/67446/

It is advisable to refer to the publisher's version if you intend to cite from the work. See Guidance on citing.

Published version at: http://www.tandfonline.com/doi/full/10.1080/02673037.2014.991379

To link to this article DOI: http://dx.doi.org/10.1080/02673037.2014.991379

Publisher: Taylor \& Francis

All outputs in CentAUR are protected by Intellectual Property Rights law, including copyright law. Copyright and IPR is retained by the creators or other copyright holders. Terms and conditions for use of this material are defined in the End User Agreement.

\section{www.reading.ac.uk/centaur}

\section{CentAUR}

Central Archive at the University of Reading

Reading's research outputs online 


\title{
Provision of Disability Adaptations to the Home: Analysis of Household Survey Data
}

\author{
Ian J. Ewart \& Chris Harty \\ School of Construction Management and Engineering \\ University of Reading \\ Whiteknights \\ Reading \\ UK \\ RG6 6AW
}

Contact Author: i.j.ewart@ reading.ac.uk

\begin{abstract}
The move towards greater provision of healthcare at home has been a significant policy intention for the last two decades (Ham et al. 2012). Key to this ambition is the need to provide suitable accommodation for disabled households by installing a range of possible adaptations. Using data from English Housing Surveys of 2003/4 and 2009/10, we compare levels of the provision of adaptations with a number of socio-cultural variables, and report on some significant correlations. This includes most importantly, bias against non-white disabled households and younger disabled households, a significant link between rented accommodation and disabled households, and a worrying increase in the proportion of adaptations deemed by the householders to be 'not needed', from $7 \%$ to $25 \%$, over that six year time period.

We discuss the context of these results and conclude with an outline plan for future research, which is urgently needed to verify and understand the issues raised.
\end{abstract}

Keywords: Adaptations, disability, discrimination, housing need, welfare state, survey data analysis.

\section{Introduction}

Delivering healthcare at home has been a significant policy intention for the last two decades (Ham et al. 2012), following research showing the substantial health benefits of remaining at home and the potential for cost savings and efficiency improvements in health and social services (Heywood and Turner 2007). Alongside this is the recognition that elderly people tend to remain in the same house for many years, which in many instances means that to maintain independent living, adaptations are required. While some research has been carried out to investigate the practical and physical suitability of residential properties for typical adaptive installations (Barlow et al. 2007; Lansley et al. 2005), several authors have pointed out the need to include socio-cultural dimensions (Dewsbury et al. 2004; Heywood 2005; Gitlin 2009; McCreadie and Tinker 2005; Oswald and Wahl 2005). This represents a growing awareness of the links between issues such as changes to the physical environment, reduced mobility, and altered perceptions of the home (Ewart and Luck 2013).

Despite this, the process for specifying and funding home adaptations remains complex and diverse (Adams and Ellison 2009; Ramsay 2010). For smaller adaptations, a 'no visit' system is promoted as good practice by the College of Occupational Therapists, who give a number of examples where this is being done (COT 2006), relying on other competent 
persons to specify simple installations. For larger projects the state-sponsored Disabled Facilities Grant (DFG) becomes the primary source of funding (Adams and Ellison 2009; DCLG 2008), but its success depends on a negotiation between the professional assessors (often occupational therapists), the professional planner (architect and/or builder), and sometimes the users themselves. This is within the context of welfare rationing ( $\mathrm{DoH} 2010$ ), which as Frances Heywood points out, depends not on understanding human need, but rather on having 'an administrative means for comparing needs and controlling the demand for public policy assistance' (2004:711). The DFG itself went through an overhaul in 2008, with changes that were intended to increase the money available, especially for medium to high cost adaptations, widen and simplify the application process, and emphasise the need for local authorities to respond to local circumstances (DCLG 2008).

In practice access to adaptations is restricted by more than medical assessment or financial considerations. Other social factors come into play, such as ownership of the property and the consequent likelihood of a landlord complying with his responsibilities to provide adequate accommodation (Williamson 2011), access to information especially in the householder's first language (Victor et al. 2012), changes to medical condition or children growing up (Heywood 2004; Peace et al. 2011). Cultural differences have also been discussed as a potential differentiating factor, so that for example South Asian families, living in multi-generational households may rely more on informal care than installed adaptations (Katbamna et al. 2004 found this to be a common idea, but in reality not the case).

On the basis that adaptations for the disabled form part of the overall scheme of welfare provision, and that this inherently means there is some degree of rationing, the question this paper seeks to investigate is what influence, if any, does socio-cultural variety play in determining the successful provision of disability adaptations?

To investigate this further, data is used from the UK Data Archive (UKDA) at two points in time - 2003 and 2009 - from a national survey of housing conditions. These surveys, whilst primarily a survey of the physical condition of the housing stock of England (e.g. DCLG 2006), also contain information about number and type of disability adaptations, and a wealth of information about each household. It has therefore been possible to compare provision of adaptations to a range of socio-cultural variables, and to see how those comparisons have changed over this 6 year period.

\section{Methodology}

\section{Datasets}

Two sets of secondary data were selected from the Economic and Social Data Service of the UKDA. The 'English House Condition Survey' (EHCS) is a continuous national survey of housing that records information relating to the type and condition of housing in England and the views of occupants. The fieldwork that gathered information for the 2003 survey (UKDA study number 6103, referred to here as EHCS2003) was carried out between April 2002 and March 2004 in over 16,000 households. The fieldworkers used a combination of detailed questionnaires (completed face-to-face), physical surveys of the house (including room size and the presence of damp for example), and some more subjective observations, such as quality of neighbourhood. ${ }^{1}$ By 2009 the EHCS had become the English Housing Survey which retained, with some slight differences, the section on disability related adaptations. Approximately 17,000 households were interviewed between April 2009 and March 2010,

\footnotetext{
${ }^{1}$ Although the degree of subjectivity was limited by specific pointers such as amount of litter and presence of graffiti, these are themselves fairly subjective measures.
} 
and at the time of writing this was the latest data available (UKDA study number 6805, referred to here as EHS2009). ${ }^{2}$

Disability adaptations form only a minor part of the total data, in the context of a survey of housing condition with particular emphasis on issues such as thermal comfort and state of repair (DCLG 2006). We acknowledge the generic problems associated with the use of secondary data (Bryman 2012), where the survey is designed for one purpose (to quantify housing conditions), but is being used for a different purpose (to examine socio-cultural links to home adaptations). This inherently frames and limits the results that can be drawn from the datasets and offers an easy critique of our discussion. For example, the majority of the information gathered during interviews came from the 'Household Reference Person' (HRP), which makes little difference for the primary purpose of the survey - housing condition - but may affect some of the socio-cultural information we are relying on. We have had to assume that using the HRP is a reasonable proxy for the whole household, and by inference, also for any other specific occupant. Similarly, the categories for 'Dwelling Age' do not differentiate post-1990, a period which has seen significant changes in care at home and new building regulations that attempt to promote 'Lifetime Homes (Carroll et al. 1999). Perhaps more importantly, one problem with the use of this data, and indeed any data set, is the accuracy and robustness of the instrument used to collect it, for example the distinction between 'adaptations' as used here, and 'equipment'. Included within the set of 24 home alterations taken from these surveys are items that are substantial and relatively permanent, such as redesigned or relocated rooms, as well as minor and portable items such as personal alarms and toilet seats, which might more accurately be called 'equipment'. Likewise, the data includes some very general terms that probably represent a range of physical changes, for example 'electrical modifications' and 'shower over bath', both of which are broad terms that could be used to describe minor pieces of equipment but also quite major adaptations. However, despite the limitations, there is a substantial amount of information in these surveys that can be used to measure the distribution of, and attitudes towards, those items referred to as adaptations, in relation to a range of social criteria. Furthermore, it is worth pointing out that we are analysing comparable data between two large-scale surveys, and that the same methodology (good or bad) is used in both. Therefore any changes between the two are unlikely to be the result of errors in one survey alone, since the quality of data remains consistent.

Most importantly, the surveys seek to identify households with a disabled occupant, and document the number and type of adaptations related to that person. This begins with the question: "For [the] person with the most severe problems getting about the house... Does your/their disability or impairment make it necessary to have adaptations in your home?" Although the question is itself neutral, the response may not be. As Mann et al. (2002) discovered, the reasons why a person who is legitimately entitled to some sort of mobility assistance declines it, are complex and varied. Not the least of these is a desire not to be seen as disabled, so that obvious adaptations such as an external ramp might be useful, but can also be seen as stigmatizing and even a demonstration of vulnerability, raising concerns for personal safety (Manzo 2003). There is also the creeping realisation of need, where the loss of mobility is a gradual process leading to ongoing resistance to assistive living for fear it amounts to an acceptance of an irreversible change in circumstances. Allowing adaptations to the home is seen as an admission that you are succumbing to old age with the inevitable loss of mobility and consequent limitations that brings (McCreadie and Tinker 2005). Conversely, there may be respondents who consider that they do need adaptations, even if an assessment

\footnotetext{
${ }^{2}$ Questions about adaptations are included on a biennial basis and the survey datasets published the following year. The 2007 data were not published following an error in survey methodology.
} 
according to current guidelines goes against that. Goldsmith's seminal work 'Designing for the Disabled' published first in 1963, and regularly updated since then (Goldsmith 1997), demonstrates that ideas and attitudes to the concept of disability and how that impacts on life at home have changed in the past and are likely to change again in the future. It seems likely therefore that some cases seen today as ineligible for assistance may be at some stage in the future. In other words, the householder's perception of need may represent genuine need, even if not recognised as such by a professional assessor.

Within the confines of this study, we have to assume that respondents who answer 'yes' to that question, are the relevant group, even though there may ambiguity and subjectivity in the question's terms 'severe problems', and 'necessary to have'. The households we use in our further analysis are therefore those who say that their mobility is impaired to the extent that they feel they need adaptations. Answering 'yes' directs the interviewer to ask the disabled householder about specific adaptations using a 'show card' listing 24 items ${ }^{3}$ and asking two further questions: "Which, if any, of the adaptations on this card are needed? (Regardless of whether you have them already)", and "Which, if any, of these adaptations do you currently have in your home? (Regardless of whether you need them)". This is as far as the survey pursues this line of enquiry, which again falls short of the ideal level of detail for our purposes. In particular, there is no follow up question that asks why any adaptations that the householder does have are not needed, a topic we return to in more detail in a later discussion. ${ }^{4}$

In accepting theses datasets at face value, we are therefore working on the assumption that some of the ambiguities and subjective interpretations of the questions are not responsible for the results we produce. This does not seem an unreasonable assumption when considering the large numbers interviewed (around 17,000 households), but may be more significant when the numbers are broken down into more specific categories. There is a balance to be struck between identifying possible relationships among ever more precise slices through the data, and the numbers who fall into those categories, which inherently become smaller. Accepting this as a potential problem, we proceed with caution and acknowledge that confirmation of some of our findings will need to come from more carefully targeted future research.

\section{Social Measures}

Within both surveys is a range of socio-cultural information which forms the basis for cross referencing with the numbers and types of adaptation outlined above. From the information available, a comprehensive list of Social Measures was drawn up including any variables that might be conceivably useful, and adjusted so that there were a manageable number of categories for each (Table 1). At this stage, the list was kept as broad as possible without prejudice, so that any patterns that emerged were equally likely to come from any of these measures. We did not assume for example that 'Ethnic Group' was any more or less likely to correlate to provision than 'Dwelling Type' or 'Tenure'. At the same time, in narrowing the possible response categories it was necessary to exercise personal judgement to provide categories that were distinct and meaningful, and yet at the same time with large enough numbers to be able to justify statistical significance. The data for 'Ethnic Group' is a good example: survey results define 8 categories for the ethnic group of the HRP, which is reduced by deriving two more variables (as used in our analysis here), one of 4 categories, and the other having only two ('white' and 'other'). There is no further differentiation of the 'white'

\footnotetext{
${ }^{3}$ EHS2009 and EHCS2003 differ slightly, but the lists were rearranged in such a way as to make them commensurate. Table 8 shows the list of 24 adaptations used.

${ }^{4}$ For the remainder of the paper, the use of the term 'household' refers to those that fall within this definition, rather than all of the households in the surveys.
} 
category, despite the fact that it accounts for over $90 \%$ of the sample as a whole. Rather bizarrely however, the ethnic group of the HRP's partner has 15 categories, although even then there are still only two 'white' categories ('white British' and 'white - other').

Thus, in choosing how we could categorise each of the measures listed in Table 1, we were directed by the data available, rather than free to choose what we might have considered to be ideal. Despite this, we have still been able to draw up a fairly comprehensive selection of attributes, many of which have previously been highlighted as potentially important in the provision of disability adaptations.

Table 1: Social Measures investigated, and possible response categories

\begin{tabular}{|c|c|c|c|c|c|c|c|c|c|}
\hline Social Measure & \multicolumn{9}{|c|}{ Responses } \\
\hline Ethnic Group & Black & White & Asian & Other & & & & & \\
\hline Dwelling Type & $\begin{array}{l}\text { Detached } \\
\text { house }\end{array}$ & $\begin{array}{l}\text { Semi- } \\
\text { Detached } \\
\text { house }\end{array}$ & $\begin{array}{l}\text { Terraced } \\
\text { House }\end{array}$ & $\begin{array}{l}\text { Converted } \\
\text { Flat }\end{array}$ & $\begin{array}{l}\text { Purpose- } \\
\text { built Flat }\end{array}$ & & & & \\
\hline Dwelling Age & Pre 1919 & $\begin{array}{l}1919- \\
1944\end{array}$ & $\begin{array}{l}1945- \\
1964\end{array}$ & $\begin{array}{l}1965- \\
1980\end{array}$ & $\begin{array}{l}1981- \\
1990\end{array}$ & $\begin{array}{l}\text { Post } \\
1990\end{array}$ & & & \\
\hline Region & $\begin{array}{l}\text { North } \\
\text { East }\end{array}$ & Yorkshire & $\begin{array}{l}\text { North } \\
\text { West }\end{array}$ & $\begin{array}{l}\text { East } \\
\text { Midlands }\end{array}$ & $\begin{array}{l}\text { West } \\
\text { Midlands }\end{array}$ & $\begin{array}{l}\text { South } \\
\text { West }\end{array}$ & $\begin{array}{l}\text { East of } \\
\text { England }\end{array}$ & $\begin{array}{l}\text { South } \\
\text { East }\end{array}$ & London \\
\hline Tenure & Own & $\begin{array}{l}\text { Rent } \\
\text { Privately }\end{array}$ & $\begin{array}{l}\text { Rent } \\
\text { from LA }\end{array}$ & $\begin{array}{l}\text { Rent from } \\
\text { Social } \\
\text { Landlord }\end{array}$ & & & & & \\
\hline $\begin{array}{l}\text { Household } \\
\text { Type }\end{array}$ & $\begin{array}{l}\text { Couple } \\
\text { without } \\
\text { children }\end{array}$ & $\begin{array}{l}\text { Couple } \\
\text { with } \\
\text { children }\end{array}$ & $\begin{array}{l}\text { Single } \\
\text { parent }\end{array}$ & Single & $\begin{array}{l}\text { Other } \\
\text { multi } \\
\text { person }\end{array}$ & & & & \\
\hline $\begin{array}{l}\text { Length } \\
\text { Residence }\end{array}$ & $<1$ year & 1 year & 2 years & $3-4$ years & $5-9$ years & $\begin{array}{l}10-19 \\
\text { years }\end{array}$ & $\begin{array}{l}20-29 \\
\text { years }\end{array}$ & $\begin{array}{l}30+ \\
\text { years }\end{array}$ & \\
\hline Type of Area & Urban & Suburban & Rural & & & & & & \\
\hline $\begin{array}{l}\text { Age of Oldest } \\
\text { Person }\end{array}$ & $16-24$ & $25-34$ & $35-49$ & $50-59$ & $60-74$ & $75-84$ & $85+$ & & \\
\hline $\begin{array}{l}\text { Socio- } \\
\text { Economic } \\
\text { Classification }\end{array}$ & $\begin{array}{l}\text { NS-SEC } \\
\text { Standard } \\
\text { categories }\end{array}$ & & & & & & & & \\
\hline $\begin{array}{l}\text { Neighbourhood } \\
\text { Quality }\end{array}$ & $\begin{array}{l}\text { Above } \\
\text { Average }\end{array}$ & Average & $\begin{array}{l}\text { Below } \\
\text { Average }\end{array}$ & & & & & & \\
\hline Income & High & $\begin{array}{l}\text { Upper } \\
\text { Middle }\end{array}$ & Middle & Low & & & & & \\
\hline
\end{tabular}

\section{Key Indicators}

Having drawn up a list of available socio-cultural and physical variables (the 'Social Measures' described above), we devised three 'Key Indicators' that would highlight different aspects of provision when cross referred with the Social Measures. These are: 'Number of Adaptations', 'Differential Provision' and 'Suitability of Provision'.

The first of these was a count of the Number of Adaptations that a household had from the list of 24 options presented to them. As can be seen from Table 8, the type of adaptation varies quite considerably, ranging from a simple grab-rail to an 'extension to meet disabled person's needs'. This latter option also highlights the vagueness that is necessary to ensure the list is relatively exhaustive, but also lacks the clarity of specific definition. While this does give some basic indication as to the levels of provision, it only works if we accept the assumption that any discrepancies are evenly spread among the various categories of each Social Measure. One important and unambiguous measure that this does provide is those households where the 'number of adaptations' is zero. To reiterate, we are limiting our analysis to those households who had answered 'yes' to the initial question asking if the 
respondent thought they needed adaptations. Therefore this gives a measure of a lack of provision, even if that observation in its own right does not tell us what adaptations the householder feels they need, from grab-rail to new extension.

Having identified that in some cases the number of adaptations provided was zero, a more nuanced indicator was required to analyse relative levels of provision. It was not possible to directly compare the presence and/or need of a specific adaptation, since many were similar or equivalent, for example the 9 separate adaptations related to the bathroom. However, by generating a difference between the numbers of adaptations present and needed, we can get a better idea of the general level of provision. The analysis of Differential Provision was carried out by counting the number of options each household 'had', along with the number of options the same household 'needed'. Since this analysis was carried out regardless of the specific adaptation, it was possible that a household could have one set of unneeded adaptations, whilst needing a similar number of different adaptations. In such a case, the difference in number would be minimal or even zero, thus inaccurately suggesting a household in no further need. However, a review of a range of many individual cases revealed that there were few, if any such households. Therefore, three categories were defined: The first was defined as being those cases where the difference between the number of adaptations 'needed' and those they 'had' was 1 or less; the second category was defined as being those cases where the difference was between 2 and 3; and the third was defined as being those cases where the difference was 4 or more. Using these three categories, we divided levels of provision into 'Have Most'; 'Need Some'; and 'Need Many'.

Relationships between these first two Key Indicators and the available Social Measures were investigated by producing cross tabulations that were examined for any significant patterns. These are discussed in more detail below, but one difference between the two time-points emerged immediately that required further analysis separate from any other correlations. The proportion of households whose number of adaptations exceeded those needed, increased markedly, rising from $3.3 \%$ in $2003 / 4$ to $20.8 \%$ in $2009 / 10$. To examine this further, for each of the 24 adaptations on the survey list a cross tabulation was carried out relating the number in situ with the number needed. This produced a series of 24 tables measuring Suitability of Provision, which showed how many households had adaptations that they considered they did not need (one example - stairlifts - is given in Table 7).

\section{Results}

\section{Summary}

After relating each of the Key Indicators to the Social Measures listed in Table 1, some significant patterns emerged. From the 2003/4 survey, we can draw attention to an apparent bias in the provision of adaptations against two social measures - ethnic group and age. ${ }^{5}$ Perhaps equally surprisingly, we do not find noticeable patterns in the relations of provision with many of the other social measures, including tenure and income, although we note a relatively high proportion of disabled homes in the rented sector. We also identify a shift in levels of provision, showing that by the time of the 2009/10 survey there was generally greater provision across all measures. However this is complicated by the final significant result, which is that by $2009 / 10$ of all the adaptations in place, the proportion not needed had increased markedly from $6.6 \%$ to $25 \%$.

\footnotetext{
${ }^{5}$ Correlations of statistical significance were confirmed by using the chi-square test, where the null hypothesis was that there is no significant difference between the expected and observed values of numbers of households with zero adaptations when related to the various social measures. A value of $p<0.05$ was deemed to refute this hypothesis and thus confirm a non-coincidental relationship.
} 
Differences between 2003 and 2009

Across the two datasets, several significant differences were readily apparent (Table 2). The proportion of the population that self-reported needing adaptations (i.e. categorised themselves as a disabled household) dropped from $11.0 \%$ in 2003 to $8.4 \%$ in 2009, but the number of adaptations provided per household increased by $22 \%$. So while the number of households reporting the need for adaptations was slightly lower, the numbers of adaptations provided substantially increased. Supporting this is the reduction in the number of households with no adaptations at all, which is approximately halved, from 311 or $17.0 \%$ in EHCS2003, to 106 or $7.6 \%$ in EHS2009.

However, this means justifying any significant relationships using our Social Measures becomes difficult in EHS2009 as the numbers are smaller and patterns of difference consequently less reliable. For example, the relationship between zero adaptations and dwelling age (Table 3) shows a discernible pattern in 2003: older dwellings are more likely to have no adaptations than newer dwellings, but this is less clear in EHS2009. ${ }^{6}$ The result might be expected, since Lansley et al. (2005) have previously pointed out that older dwellings are generally more difficult to adapt than newer dwellings, but our data only provides weak confirmation. The same can be said of other patterns that are evident in the earlier data but masked in the later data. Instead we are able to comment on bias apparent in the 2003/4 data, and consider below the implications of the increased provision of adaptations by $2009 / 10$, in 'Suitability of Provision'.

Table 2: Number of Adaptations

\begin{tabular}{|c|c|c|c|}
\hline & EHCS2003 & EHS2009 & Change \\
\hline $\begin{array}{l}\text { Survey Size } \\
\text { (total no. of households) }\end{array}$ & 16648 & 17042 & $+2.4 \%$ \\
\hline $\begin{array}{l}\text { Require adaptations } \\
\text { (no. of 'disabled households') }\end{array}$ & $\begin{array}{c}1828 \\
11.0 \%\end{array}$ & $\begin{array}{l}1396 \\
8.2 \%\end{array}$ & $-2.8 \%$ \\
\hline $\begin{array}{l}\text { Disabled households with zero } \\
\text { adaptations }\end{array}$ & $\begin{array}{c}311 \\
17.0 \% \\
\end{array}$ & $\begin{array}{c}107 \\
7.7 \%\end{array}$ & $-9.3 \%$ \\
\hline $\begin{array}{l}\text { Adaptations in situ } \\
\text { (total no.) }\end{array}$ & 3940 & 3774 & \\
\hline $\begin{array}{l}\text { Adaptations in situ per household } \\
\text { (total survey) }\end{array}$ & 0.24 & 0.22 & $-8.3 \%$ \\
\hline $\begin{array}{l}\text { Adaptations in situ per household } \\
\text { (where required) }\end{array}$ & 2.16 & 2.70 & $+25.0 \%$ \\
\hline
\end{tabular}

\section{Regional Variation}

Among the nine possible responses to 'Region' there was some variation, but no obvious pattern. The spread of 'needing many' adaptations ranged from 7\% (Yorkshire and East of England) to $12 \%$ (North West and London), but it seems that the difference is not strongly related to geographical location. There is a slightly stronger pattern when using the 'Type of Area' measure that may explain the differences better. In rural areas 78\% 'have most' and 7\% 'need many' adaptations, whereas in urban areas the equivalent figures are $65 \%$ and $14 \%$ (suburban areas are intermediate for both figures). To speculate further, there may be a link to tenure, in that London has the highest proportion of rented accommodation in England and Wales (50.4\% in 2011), however the region with the third highest is Yorkshire (35.5\%). This suggests that there is likely to be a more complex set of relationships driving regional variation, possibly including a rural/urban divide or issues to do with tenure.

${ }^{6} \mathrm{p}=0.26$ 
Table 3: Zero Adaptations vs Dwelling Age

\begin{tabular}{|c|c|c|c|c|c|c|}
\hline \multirow{3}{*}{$\begin{array}{l}\text { Dwelling Age } \\
\text { (by category) }\end{array}$} & \multicolumn{3}{|c|}{ EHCS2003 } & \multicolumn{3}{|c|}{ EHS2009 } \\
\hline & \multirow[t]{2}{*}{$\begin{array}{c}\text { No. Disabled } \\
\text { Households } \\
\end{array}$} & \multicolumn{2}{|c|}{$\begin{array}{c}\text { With Zero } \\
\text { Adaptations }\end{array}$} & \multirow[t]{2}{*}{$\begin{array}{c}\text { No. Disabled } \\
\text { Households }\end{array}$} & \multicolumn{2}{|c|}{$\begin{array}{c}\text { With Zero } \\
\text { Adaptations }\end{array}$} \\
\hline & & No. & $\%$ & & No. & $\%$ \\
\hline Pre 1919 & 232 & 49 & 21.1 & 173 & 14 & 8.1 \\
\hline 1919 - 1944 & 321 & 62 & 19.3 & 229 & 19 & 8.3 \\
\hline $1945-1964$ & 548 & 91 & 16.6 & 415 & 34 & 8.2 \\
\hline $1965-1980$ & 455 & 76 & 16.7 & 351 & 20 & 5.7 \\
\hline $1981-1990$ & 181 & 22 & 12.2 & 143 & 8 & 5.6 \\
\hline Post 1990 & 90 & 11 & 12.2 & 85 & 11 & 12.9 \\
\hline Full Sample & 1828 & 311 & 17.0 & 1396 & 106 & 7.6 \\
\hline
\end{tabular}

\section{Tenure}

As an owner-occupier, adapting the home is restricted primarily by funding, but as the data here shows that the majority of disabled households are in rented accommodation, the role of the landlord is an important consideration. Problems vary according to whether the property is rented privately, or from a Registered Social Landlord, or a Local Authority. Social landlords report being frustrated by the complexities and inconsistencies of funding provision (Ramsay 2010; Adams and Ellison 2009), whereas private landlords are more inclined to obstruct the installation of adaptations (Williamson 2011). As the property owner, their permission is required before work can be carried out, but its denial could be interpreted as discrimination, a situation that can only be redressed through the courts. Funding through the DFG includes a grant condition that there is an intention that the occupant remains in the dwelling for a period of five years, which must include the landlord's consent. Landlords may feel constrained by such a long term agreement and prefer that the tenant moves out rather than carrying out adaptations. This can be done legally by giving notice within the terms of the tenancy agreement, or refusing to renew the agreement and allowing it to lapse. Even these scenarios assume that the landlord is prepared to abide by his legal obligations, which of course many do not, instead simply ignoring their responsibilities (Williamson 2011). It is difficult and impractical to pursue a reluctant landlord, especially if the tenant is vulnerable, and so the prospect emerges of a lack of suitably adapted accommodation for a disabled household.

From our analysis however, there are only weak links between the type of tenure and the provision of disability adaptations (see Table 4$).{ }^{7}$ A similar number of homes that are owned (either outright or mortgaged) have zero adaptations to those that are rented $(21 \% \mathrm{vs}$ $18 \%$ ), with a slightly lower figure for those renting from a Registered Social Landlord (15\%). As is confirmed by the more subtle analysis of Differential Provision, there are no significant differences between rented and owned properties.

However, it is striking that the households used as the basis for our analysis here (those who self-report the need for disability adaptations to their home), are disproportionately over-represented in the rental sector. $65.4 \%$ of all those households who report the need for disability adaptations are renting, whether from local authority, Registered Social Landlord or privately. From the 2011 census of England and Wales in figures given by the Office for National Statistics (ONS 2013), nationwide the proportion of rented accommodation is $36 \%$, a rise from $31 \%$ in 2001 . So while we do not see a difference in the actual provision of adaptations related to tenure, self-reported disabled households, when compared to the national average, are twice as likely to live in rented accommodation.

${ }^{7} \mathrm{p}=0.26$ 
Table 4: Variations in number of adaptations according to Tenure (EHCS2003)

\begin{tabular}{|c|c|c|c|c|c|c|c|}
\hline \multirow[b]{2}{*}{ Tenure } & \multicolumn{2}{|c|}{ Households requiring adaptations } & \multicolumn{2}{|c|}{ Households with zero adaptations } & \multicolumn{3}{|c|}{$\begin{array}{c}\text { Differential Provision } \\
(\%)\end{array}$} \\
\hline & Number & $\begin{array}{c}\text { Proportion of } \\
\text { Total }(\%) \\
\end{array}$ & Number & $\%$ of category & $\begin{array}{l}\text { Have } \\
\text { Most } \\
\end{array}$ & $\begin{array}{l}\text { Need } \\
\text { Some } \\
\end{array}$ & $\begin{array}{l}\text { Need } \\
\text { Many } \\
\end{array}$ \\
\hline Own & 633 & 34.6 & 99 & 15.6 & 74.8 & 16.0 & 9.2 \\
\hline Rent from LA & 674 & 36.9 & 126 & 18.7 & 67.2 & 21.4 & 11.4 \\
\hline Rent from RSL & 411 & 22.5 & 62 & 15.1 & 73.7 & 18.0 & 8.3 \\
\hline Rent Privately & 110 & 6.0 & 24 & 21.8 & 67.3 & 18.2 & 14.5 \\
\hline Rent Total & 1195 & 65.4 & 212 & 17.7 & 69.5 & 19.9 & 10.6 \\
\hline Survey Total & 1828 & 100.0 & 311 & 17.0 & 71.3 & 18.5 & 10.1 \\
\hline
\end{tabular}

\section{Ethnic Group}

Relating provision to ethnic groups provided one of the most noticeable differences in the EHCS2003 survey. On a number of measures, the data suggest that non-white households are more in need of disability adaptations than white households. These results need to be tempered by the observation that the numbers of non-white households who report needing adaptations are relatively small. Table 5 gives results as four separate categories, but these are also summed into two coarse categories (white and non-white) to increase numbers and hence reliability at the expense of detail. This shows that non-white households are twice as likely to have no adaptations at all (15.6\% vs $37.6 \%),{ }^{8}$ while the average number of adaptations per household drops from 2.20 for whites to 1.52 for non-whites. This is reinforced by the Differential Provision indicator, which measures the scale of need for adaptations when compared to that already provided. Fewer non-white households had what they needed (56.4\% vs $72.4 \%$ ), and more non-white households reported needing many more adaptations $(21.4 \%$ vs $9.4 \%)$. While the numbers available in the survey limit the extent to which these results can be extrapolated to the wider population, overall this provides strong evidence for reduced accessibility to adaptations for non-white households.

Table 5: Variations in number of adaptations according to Ethnic Group (EHCS2003)

\begin{tabular}{|l|c|c|c|c|c|c|c|c|}
\hline & \multicolumn{3}{|c|}{ Adaptations provided } & \multicolumn{2}{c|}{$\begin{array}{c}\text { Households with zero } \\
\text { adaptations }\end{array}$} & \multicolumn{3}{c|}{$\begin{array}{c}\text { Differential Provision } \\
\text { (\%) }\end{array}$} \\
\hline $\begin{array}{l}\text { Ethnic } \\
\text { Group }\end{array}$ & Number & $\begin{array}{c}\text { Number of } \\
\text { Households }\end{array}$ & $\begin{array}{c}\text { Per } \\
\text { Household }\end{array}$ & Number & $\begin{array}{c}\text { Have } \\
\text { Meed } \\
\text { category }\end{array}$ & $\begin{array}{c}\text { Need } \\
\text { Some }\end{array}$ & Many \\
\hline White & $\mathbf{3 7 6 2}$ & $\mathbf{1 7 1 1}$ & $\mathbf{2 . 2 0}$ & $\mathbf{2 6 7}$ & $\mathbf{1 5 . 6}$ & $\mathbf{7 2 . 4}$ & $\mathbf{1 8 . 3}$ & $\mathbf{9 . 4}$ \\
\hline Black & 66 & 41 & 1.61 & 14 & 34.1 & 58.5 & 19.5 & 22.0 \\
\hline Asian & 83 & 60 & 1.38 & 24 & 40.0 & 51.7 & 21.7 & 26.7 \\
\hline Other & 29 & 16 & 1.81 & 6 & 37.5 & 68.8 & 31.3 & 0.0 \\
\hline $\begin{array}{l}\text { Non-white } \\
\text { total }\end{array}$ & $\mathbf{1 7 8}$ & $\mathbf{1 1 7}$ & $\mathbf{1 . 5 2}$ & $\mathbf{4 4}$ & $\mathbf{3 7 . 6}$ & $\mathbf{5 6 . 4}$ & $\mathbf{2 2 . 2}$ & $\mathbf{2 1 . 4}$ \\
\hline $\begin{array}{l}\text { Full Survey } \\
\text { total }\end{array}$ & 3940 & 1828 & 2.16 & 311 & 17.0 & 71.3 & 18.5 & 10.1 \\
\hline
\end{tabular}

Age

A significant pattern also emerges in the relationship between the 'age of oldest resident' and the numbers of adaptations (Table 6). ${ }^{9}$ Dividing the ages into two groups, separated at the age of 60 shows that the younger disabled are much more likely to have no adaptations at all

\footnotetext{
${ }^{8} \mathrm{p}=9.4 \mathrm{E}-215$

${ }^{9} \mathrm{p}=7.7 \mathrm{E}-17$
} 
$(28 \%$ vs $12 \%) .{ }^{10}$ As can also be seen, the increase in provision from youngest to oldest is gradual but consistent, from around 50\% with zero adaptations under the age of 35 to around $10 \%$ with zero adaptations over the age of 75 . This is reinforced when looking at Differential Provision, which shows the same pattern of increased provision with age, but also highlights a substantial discrepancy in those needing many more adaptations. This drops from $27 \%$ of the youngest to $7 \%$ of the oldest. As a measure of perceived need, this represents both the amount provided and the degree to which it meets needs, so for a substantial proportion of the younger disabled, their needs went largely unmet in 2003/4. This may be reinforced using the data relating to household type, by dividing the results into two categories, those without children, and those with children or 'other multi-person households'. The former category (no children) is about $10 \%$ more likely to have all or most of the adaptations that they need than the latter, but the numbers with children are small, and there is not enough detail to confidently assume 'multi-person households' means it includes children, let alone a disabled child.

Table 6: Variations in number of adaptations according to Age (EHCS2003)

\begin{tabular}{|l|c|c|c|c|c|c|}
\hline & $\begin{array}{c}\text { Households requiring } \\
\text { adaptations }\end{array}$ & \multicolumn{2}{|c|}{$\begin{array}{c}\text { Households with zero } \\
\text { adaptations }\end{array}$} & \multicolumn{3}{|c|}{$\begin{array}{c}\text { Differential Provision } \\
\text { (\%) }\end{array}$} \\
\hline $\begin{array}{c}\text { Age of Oldest } \\
\text { person in household }\end{array}$ & Number & Number & $\begin{array}{c}\text { \% of } \\
\text { category }\end{array}$ & $\begin{array}{c}\text { Have } \\
\text { Most }\end{array}$ & $\begin{array}{c}\text { Need } \\
\text { Some }\end{array}$ & $\begin{array}{c}\text { Need } \\
\text { Many }\end{array}$ \\
\hline $16-24$ & 11 & 5 & 45.5 & 54.5 & 18.2 & 27.3 \\
\hline $25-34$ & 43 & 23 & 53.5 & 55.8 & 20.9 & 23.3 \\
\hline $35-49$ & 244 & 77 & 31.6 & 60.2 & 23.4 & 16.4 \\
\hline $50-59$ & 257 & 51 & 19.8 & 64.2 & 21.4 & 14.4 \\
\hline Under 60 Total & $\mathbf{5 5 5}$ & $\mathbf{1 5 6}$ & $\mathbf{2 8 . 1}$ & $\mathbf{6 1 . 6}$ & $\mathbf{2 2 . 2}$ & $\mathbf{1 6 . 2}$ \\
\hline $60-74$ & 590 & 89 & 15.1 & 72.7 & 19.5 & 7.8 \\
\hline $75-84$ & 506 & 50 & 9.9 & 78.5 & 14.2 & 7.3 \\
\hline 85 or over & 177 & 16 & 9.0 & 76.8 & 16.4 & 6.8 \\
\hline Over 60 Total & $\mathbf{1 2 7 3}$ & $\mathbf{1 5 5}$ & $\mathbf{1 2 . 2}$ & $\mathbf{7 5 . 6}$ & $\mathbf{1 7 . 0}$ & $\mathbf{7 . 5}$ \\
\hline Survey Total & 1828 & 311 & 17.0 & 71.3 & 18.5 & 10.1 \\
\hline
\end{tabular}

\section{Other Social Measures}

Described above are the more noticeable patterns that relate provision of disability adaptations to the available Social Measures in EHCS2003. Of the others that we considered, there are further patterns that would warrant further investigation, although as with the issues related to regional variation described above, the data available here is not sufficiently detailed or targeted to provide anything more than reasonable speculation; either there are no obvious patterns, or the degree of change is small.

As might be expected from Lansley et al. (2005), there are differences in levels of provision depending on dwelling type and age, potentially confirming their conclusions that converted flats and older buildings are less likely to have adaptations, although this is not a statistically significant relationship. ${ }^{11}$ Analysing length of residence also appears to demonstrate what we might intuitively expect, in that there is a gradual increase in the levels of provision and satisfaction of perceived need the longer the householder has been living at the same address. This does not change appreciably after 5 years of residence, so it may be that initial installations in the first few years of residence are more important than the longer term continual changes.

\footnotetext{
${ }^{10} 65$ might have been a more useful distinction as the common age of retirement with all its related changes, but the data gathered in these surveys has the closest category break at 60 years of age.

${ }^{11} \mathrm{P}=0.13$
} 
Whilst the measure of neighbourhood quality does suggest an increase in provision for the 'better' neighbourhoods, we are reluctant to attribute a causal effect to this on the basis that the criteria used to define quality are fairly arbitrary, and depend on individual fieldworker's judgement. When seen in conjunction with household income, which might be a reasonable correlate, and which does not show a pattern of provision, this seems tentative at best.

\section{Suitability of Provision}

As discussed above, during the time period under review here, there was a substantial increase in the number of adaptations provided, rising by $22 \%$ from 2.16 adaptations per household in 2003/4 to 2.64 in 2009/10. Similarly the number of households with no adaptations at all, despite a stated need, dropped from $17 \%$ to $7.6 \%$ (see Table 2). Greater provision might be expected to satisfy outstanding need, but this increase seemed to go beyond that, as we also identified an increase in the numbers of households who reported having more adaptations than they needed. In EHCS2003 this represented 3.3\% of disabled households, rising to $20.8 \%$ for EHS2009.

To investigate this further, a comparison was made for each of the 24 adaptation options, tabulating whether a household had the item or not, versus whether they needed the item or not. Using one particular adaptation - the stairlift - to illustrate the data (Table 7), it can be seen that the proportion of households who had a stairlift but did not need it stood at $2.7 \%$ in EHCS2003, and 16.7\% in EHS2009. From similar tables for each of the 24 options an equivalent figure for the adaptations provided when not needed can be collated (Table 8). This shows that of the 3774 adaptations provided to householders in the EHS2009 survey, 943 or $25 \%$ are not needed. This has risen from a figure of $6.6 \%$ in EHCS2003. Possible causes for this change are discussed in more detail below, but essentially this might be a positive outcome of the increased influence of the Lifetime Homes agenda (Hanson 2001; Carroll et al. 1999), the introduction of new building regulations (HM Govt. 2010), or more worryingly, a surge in poorly targeted provision.

Table 7: Suitability of Provision: Stairlifts 2003/4 \& 2009/10

\begin{tabular}{|l|c|c|l|}
\hline & EHCS2003 & EHS2009 & $\begin{array}{c}\text { Change } \\
\text { 2003 to 2009 }\end{array}$ \\
\hline Number of Disabled Households & 1828 & 1396 & \\
\hline Those who NEED a stairlift & 287 & 216 & No change \\
& $15.7 \%$ & $15.5 \%$ & \\
\hline Those who HAVE a stairlift & 150 & 156 & Small increase \\
\hline Those who NEED a stairlift but & $8.2 \%$ & $11.2 \%$ & \\
do not HAVE one & 141 & 86 & Small decrease \\
\hline $\begin{array}{l}\text { Those who HAVE a stairlift but } \\
\text { do not NEED one. }\end{array}$ & $4.4 \%$ & $6.9 \%$ & \\
\hline
\end{tabular}

\section{Discussion}

From these results it is clear that the scope of disability adaptations provision reported in the English Housing Survey of 2009/10 (EHS2009) is more generous than that reported in equivalent data from the 2003/4 English House Condition Survey (EHCS2003), with a 22\% increase in numbers of adaptations per household. Along with this is a consequent halving of the number of households with no adaptations at all (dropping from 17\% to 7.6\%). However, 
the distribution of adaptations is in several ways uneven, and this deserves further attention and explanation.

\section{Bias according to Ethnic Group}

Evidence for bias in the provision of adaptations associated with ethnicity is demonstrated by a distinct difference in the numbers and suitability of adaptations between white and nonwhite households from the figures available in EHCS2003, such that non-white households were then more than twice as likely to have no adaptations as white households, twice as likely to need many more adaptations, and significantly less likely to have most of the adaptations they needed. By the time of EHS2009, the general increase in provision masks any potential bias so that all groups have much lower levels of perceived outstanding need. This is a mixed result, since if these problems have not been detected or understood there is a strong possibility that they remain. If there is a genuine bias in favour of white over nonwhite disabled households, then we need to understand why.

Previous research has highlighted the importance of cultural sensitivity when assessments are made for suitable adaptations (Heywood 2004), suggesting that this is a current, or at least recent issue. Any research that has looked specifically at ethnic or cultural differences in disabled living at home has focussed almost exclusively on Asian communities (Victor et al. 2012; Katbamna et al. 2004), which limits the academic foundations on which we can build our argument. However in the body of work that has been done, Katbamna et al. (2004) took as their starting point the suggestion that multi-generational Asian households were culturally adapted, even required, to provide informal care to elderly family members. If this were true, then the need for other forms of assistance, such as home adaptations, might be reduced and lead to a lower uptake. They found this not to be the case, a result which has subsequently been confirmed by Victor et al. (2012) for particular South Asian groups, and is currently being expanded by them into other ethnic minorities including African, Caribbean and Chinese communities.

The anecdotal nature of Katbamna et al.'s initial suspicions suggests that there may be a wider perception within the healthcare professions that Asian households are socially structured to provide care for family members. It may also be the case that culturally rooted practices make the provision of adaptations more difficult. For example, traditional Asian practices of sitting and sleeping on the floor have been shown to affect limb joints, and rehabilitation following medical interventions required a significant change in behaviour (Kim et al. 2010). In that case, knee replacement surgery meant a far greater proportion of patients resorted to sitting on chairs and sleeping on beds than previously, when their cultural norm was not to use such furniture. Some of the equipment that would normally be specified on the basis of medical assessment, typically done according to a comparison of specific impairments with the demands of the home environment (COT 2006; Dept. of Health 2010; Gitlin 2003), is likely to be at odds with these cultural requirements. For example hoists designed to lift and lower patients into bed are not suitable for lifting and lowering patients to the floor. Current policy advice to pay more attention to the user's experience goes some way to acknowledge the prospect of incompatibility in schemes of assessment (COT 2006; see also Gitlin 2009; Heywood 2004), between those issues seen as medically pertinent and the patient's notion of their future life. 
Table 8: Adaptations provided but not needed

\begin{tabular}{|l|c|c|c|c|c|c|c|}
\hline & \multicolumn{2}{|c|}{$\begin{array}{c}\text { Lifetime } \\
\text { or } \\
\text { Adaptation }\end{array}$} & \multicolumn{2}{|c|}{$\begin{array}{c}\text { No. households that } \\
\text { have the adaptation }\end{array}$} & \multicolumn{2}{c|}{$\begin{array}{c}\text { No. households that } \\
\text { do not need } \\
\text { adaptation }\end{array}$} & \multicolumn{2}{c|}{ \% Not needed } \\
& & $\mathbf{2 0 0 3 / 0 4}$ & $\mathbf{2 0 0 9 / 1 0}$ & $\mathbf{2 0 0 3 / 0 4}$ & $\mathbf{2 0 0 9 / 1 0}$ & $\mathbf{2 0 0 3 / 0 4}$ & $\mathbf{2 0 0 9 / 1 0}$ \\
\hline Internal Ramp & $\mathrm{L}$ & 39 & 47 & 5 & 20 & 12.8 & 42.6 \\
\hline Grab/Hand/Stair Rail & $\mathrm{D}$ & 921 & 718 & 31 & 149 & 3.4 & 20.8 \\
\hline Wide Doorways & $\mathrm{L}$ & 112 & 132 & 6 & 33 & 5.4 & 25.0 \\
\hline Electrical Modifications & $\mathrm{L}$ & 61 & 45 & 3 & 10 & 4.9 & 22.2 \\
\hline Additional Heating & $\mathrm{L}$ & 47 & 64 & 0 & 24 & 0.0 & 37.5 \\
\hline Entry Phone & $\mathrm{L}$ & 88 & 112 & 6 & 49 & 6.8 & 43.8 \\
\hline Individual Alarm & $\mathrm{D}$ & 155 & 150 & 14 & 49 & 9.0 & 32.7 \\
\hline Hoist & $\mathrm{D}$ & 58 & 46 & 3 & 13 & 5.2 & 28.3 \\
\hline Stairlift & $\mathrm{D}$ & 150 & 156 & 4 & 26 & 2.7 & 16.7 \\
\hline Graduated Shwr Floor & $\mathrm{L}$ & 110 & 148 & 7 & 21 & 6.4 & 14.2 \\
\hline Low Level Bath & $\mathrm{D}$ & 71 & 53 & 4 & 16 & 5.6 & 30.2 \\
\hline Shower over Bath & $\mathrm{L}$ & 282 & 192 & 26 & 91 & 9.2 & 47.4 \\
\hline Shower Replacing Bath & $\mathrm{D}$ & 251 & 255 & 7 & 46 & 2.8 & 18.0 \\
\hline New Bath/Shwr room & $\mathrm{L}$ & 76 & 128 & 2 & 38 & 2.6 & 29.7 \\
\hline Redesigned Bathroom & $\mathrm{L}$ & 91 & 152 & 6 & 49 & 6.6 & 32.2 \\
\hline Redesigned Kitchen & $\mathrm{L}$ & 44 & 63 & 2 & 18 & 4.5 & 28.6 \\
\hline Relocated Bath/Shwr room & $\mathrm{L}$ & 29 & 58 & 1 & 24 & 3.4 & 41.4 \\
\hline Additional/Relocated Toilet & $\mathrm{L}$ & 58 & 72 & 4 & 20 & 6.9 & 27.8 \\
\hline Bath/Shower Seat & $\mathrm{D}$ & 569 & 515 & 41 & 112 & 7.2 & 21.7 \\
\hline Special/Raised Toilet Seat & $\mathrm{D}$ & 423 & 359 & 53 & 63 & 12.5 & 17.5 \\
\hline Adjustable Bed & $\mathrm{D}$ & 168 & 188 & 21 & 38 & 12.5 & 20.2 \\
\hline Other Kitchen Modifications & $\mathrm{D}$ & 51 & 36 & 6 & 13 & 11.8 & 36.1 \\
\hline Extension & $\mathrm{D}$ & 26 & 51 & 2 & 9 & 7.7 & 17.6 \\
\hline Visual/Hearing adaptations & $\mathrm{D}$ & 60 & 34 & 6 & 12 & 10.0 & 35.3 \\
\hline & & & & & & & \\
\hline Lifetime adaptations total & & 1037 & 1213 & 68 & 397 & 6.6 & 32.7 \\
\hline Disability adaptations total & & $26.3 \%$ & $32.1 \%$ & & & & \\
\hline TOTALS & & $73.4 \%$ & $67.9 \%$ & 192 & 546 & 6.6 & 21.3 \\
\hline & & $\mathbf{3 9 4 0}$ & $\mathbf{3 7 7 4}$ & $\mathbf{2 6 0}$ & $\mathbf{9 4 3}$ & $\mathbf{6 . 6}$ & $\mathbf{2 5 . 0}$ \\
\hline
\end{tabular}

Bias according to Age

Further evidence for bias across minority groups in EHCS2003 comes from the data related to age. Whilst non-white households represent around $6 \%$ of the total who report the need for disabled adaptations, the equivalent figure for the under-60s is around $30 \%$. In the context of this sample the younger disabled population is in the minority, and the data from EHCS2003 show a pattern favouring the older rather than the younger disabled community. Where the age of the oldest person in the household is less than 60, the chance of having no adaptations at all is more than double that of the over-60 householder (28\% to $12 \%)$. The link between Differential Provision and age reinforces this basic observation, showing a pattern of increasing provision of necessary adaptations in line with age, so that only around half of the youngest 'have most' of what they need and a quarter 'need many more' adaptations (see Table 6). Imrie has written about the effect of the physical layout of the home on the lives of disabled people (e.g. 2004a), highlighting the particular difficulties of the younger disabled person, especially those who remain in robust physical and mental health but are obligatory wheelchair users (see also Harris 2010). Research into inclusive design, especially the concept of the Lifetime Home (Hanson 2001; Dewsbury et al. 2004), has shown the need to 
better understand the heterogeneity of the disabled community, and the consequent variety in suitable housing. However, much of the rhetoric surrounding the political agenda to shift responsibility for healthcare away from state institutions and on to the individual and their community (Björnsdóttir 2002) is based on the priority given to the ageing population as a problem to be solved (Ham et al. 2012), especially using ICT (3 MillionLives 2012). Homebased healthcare has been justified with socio-economic arguments about the benefits of better care, reduced costs, and opportunities for business in developing new products (but see Steventon et al. 2012 for a critical assessment of the potential benefits of telecare), with most resources targeted at the elderly.

Generalizing the housing needs of the disabled by particularizing the needs of the elderly, as suggested by our data, seems to have resulted in a system which prioritizes devices and services for the over-60s at the expense of the younger disabled population. As they are the majority (representing around $70 \%$ of the disabled population in the surveys used here), there are greater economic benefits to be had by targeting that group. Elderly patients tend to need longer and more expensive treatments, require support to return home that may be difficult to organise (Heywood and Turner 2007), and can be assisted in living at home through the use of new technologies and devices (Barlow et al. 2007). The emphasis on the provision of home-based care for the elderly, coupled with greater market-oriented opportunities for suppliers to this part of the population has created a situation where it is seen as more valuable to help the elderly than the younger disabled.

\section{Provision related to Tenure and House Type}

The results when considering the potential for variability in provision according to tenure appear at first glance to demonstrate that there are no obvious links between ownership and the type or number of adaptations provided. This is despite anecdotal evidence suggesting that landlords, especially private landlords, are inclined to obstruct the installation of adaptive devices (Williamson 2011). Whilst our evidence seems to contradict that assertion, it also demonstrates the extent to which disabled householders rely on the rental sector for their accommodation, since they are twice as likely to be living in rented housing as those households who did not report the need for adaptations. The proportion of disabled owneroccupiers at 35\% compares with a national average of 64\% in 2011 and $69 \%$ in 2001 (ONS 2013). Taken together, the high numbers of disabled renters and the evidence for reluctant landlords, who prefer not to consent to adaptations, suggests an uneasy interdependence between the private rental sector and disabled living.

A less unexpected point that comes from this study is the support it lends to Lansley et al. (2005) in highlighting the difficulties of adapting certain types of home. In their study, they showed that the type of adaptations that could be provided was restricted by, amongst other things, architecture. In both EHCS2003 and EHS2009 'Converted Flats' (Lansley et al.'s most problematic category) had the lowest rate of adaptation but also the lowest numbers overall. Similarly, when looking at dwelling age (see Table 3) there is an apparent pattern of increased likelihood for older buildings to have no adaptations compared with newer buildings, with one exception - the 'post 1990' dwellings. This observation is tempered by the weak statistical correlation, ${ }^{12}$ but in common with previous observations, this shows that more adaptations were provided generally, but not it seems to the most recent buildings. This may be due to the introduction of new Part M building regulations in 2004 that established requirements to provide greater accessibility to all users, including wider doorways, fewer level changes per floor and a wheelchair-practical downstairs toilet (HM Govt. 2010). Some of these are equivalent to retrofitted adaptations, thus rendering them

${ }^{12} \mathrm{p}=0.13$ for EHCS2003; $\mathrm{p}=0.26$ for EHS2009 
unnecessary, hence increasing the numbers of newer homes without any adaptations. The definition of dwelling age categories in these surveys could easily be updated for future surveys to include pre- and post- 2004 to provide information on the effect of that new legislation. It may be for example that there is a lower perception of need for houses that comply with Part $\mathrm{M}$ building regulations, regardless of whether this truly satisfies the householder's actual needs, since, according to Imrie (2004b) major house-builders are inclined to build to the minimum standard and have little interest in the spirit of the regulations.

\section{Suitability of Adaptations}

Having shown that the overall provision of adaptations increased between 2003/4 and 2009/10, the data show a substantial increase in the numbers of adaptations that were deemed by their recipients to be not needed. A simple count of the number of adaptations in place, regardless of what they are, reveals that of all the disabled households in EHS2009, 20\% had more than they needed, compared with only 3\% in EHCS2003. More specifically, as listed in Table 8, by the time of EHS2009 of all the adaptations that had been provided, $25 \%$ were deemed by the householders not to be needed. This is a dramatic increase from the equivalent figure of $6.6 \%$ in EHCS2003, and is consistent across all types of adaptation. ${ }^{13}$

What we called 'Suitability of Provision' would be expected to include a proportion of adaptations that were not needed, as shown in previous research following up the use patterns of assistive technologies (Hoffmann and McKenna 2004; McCreadie and Tinker 2005), but this does not explain why there should have been such a substantial change. The data is not sufficiently detailed to definitively suggest causes, but there are contradictory possibilities: it may be that the installations have been supplied without due regard for the needs of the occupants and users; or it may be that the housing stock is acquiring aspects of lifetime homes. In the first case, this suggests a problem with the process of specifying and funding adaptations for disabled households, but the second suggests a beneficial move towards greater preparation for an increasingly elderly population.

We can gain some insights by considering in more detail the types of adaptations listed here and relating these to some of the adaptations that are becoming more mainstream. Part M building regulations (HM Govt. 2010) have applied to all new buildings since 1999, and essentially deal with access, and especially for wheelchair users, either as current or future home-owners, or as visitors. This includes level access into and through the house, wider doorways, lower switches and sockets, and a wheelchair friendly ground floor WC, along with considerations for future use, such as the allocation of downstairs space for a bed (Carroll et al. 1999). These are relevant criteria for new build houses, but do not address the majority of properties, which of course have been designed and built according to much older standards and ideas. Hanson (2001) suggests that the two main issues that prevent what she calls 'architectural emancipation' are difficult changes in level and insufficient space. This represents one part of her argument that true Lifetime Homes must form part of a complete system including a wide range of issues such as new forms of ownership, access to transport, care packages etc. When looking through the list of adaptations from these surveys it is difficult to identify with any great certainty specific items that could be definitely attributed to the increasing provision of Lifetime Homes, or disability adaptations made specifically for the current occupant. We can make some informed assumptions on the basis of the ideas put

13 Despite the many shortcomings discussed in the text, one advantage of large scale surveys is that by maintaining a consistent methodology, error rates remain constant. Issues such as interviewee misunderstandings are therefore equally likely between the two surveys used here, so that any observable patterns of change are likely to be statistically significant and not unduly skewed by individual cases 
forward by Imrie (2004a; b), Hanson (2001) and the 16 design criteria developed by the Joseph Rowntree Foundation (Carroll et al. 1999). ${ }^{14}$ Referring back to Table 8, we have separated out those items that might be reasonably considered part of the Lifetime Homes agenda (called ' $\mathrm{L}$ ' in Table 8), and others that might be considered specific 'disability adaptations' (called 'D'). If there is a progressive move towards greater numbers of adaptations that form part of the drive for Lifetime Homes, then as far as is possible within these data, we would expect to see a significant difference between those items we have defined as ' $\mathrm{L}$ ', and those defined as ' $\mathrm{D}$ '. In particular we might expect to see a greater increase in the proportion of ' $L$ ' adaptations that the householder defines as 'not needed' on the basis that they are provided for future use, or the use of visitors. To some extent this is visible in Table 8 , where the proportion of 'not needed' rises from $6.6 \%$ to $32.7 \%$, whereas the increase for ' $\mathrm{D}$ ' adaptations rises from $6.6 \%$ to $21.3 \%$. However, within the limits of the survey data used, the dominant picture remains one where there is a substantial increase across the board in the numbers of adaptations provided that the householders consider not to be needed.

Various researchers have pointed out the link between social issues and perceptions of need for disability-related assistive devices, including stigma and loss of independence (Mann et al. 2002), indignity and disempowerment (Heywood 2004), and the inherent tension between the patient's felt need and medically assessed need, and the effect this has on the concept of home (McCreadie and Tinker 2005; Angus et al. 2005). Specifying adaptations is done by occupational therapists trying to resolve this tension according to their training and experience (Gitlin 2009; Fänge and Iwarsson 2007) and within a government framework of eligibility (DoH 2010). The degree to which the patient's own knowledge is incorporated into this assessment depends on the individual therapist and, according to the report by Heywood et al. (COT 2006), is often advocated but usually overlooked (see also Gitlin 2009). This positions the clinical perspective as the default position, over-riding and sometimes disregarding the patient's experience, resulting in adaptations that may not be useful and are sometimes actively harmful (Heywood 2004).

This is complicated by the fact that changes are ongoing and sometimes rapid, as in the case of some elderly patients (Niva and Skar 2006). Regardless of illness or disability, change also occurs through life (Dewsbury et al. 2004; Johansson et al. 2009) - sleep patterns, relationships with family and friends and so on - so that the domestic environment, including its adaptations, becomes part of a dynamic system. Adaptations to the home such as those listed in the surveys used here are fixed and relatively inflexible, reduced to either being in place or not. ${ }^{15}$ In the absence of any flexibility in the adaptation itself, or the building that contains it, coping with a dynamic health condition is therefore reliant on patients constantly altering their daily routines and compromising their cultural practices to suit the adaptation (Niva and Skar 2006; Gitlin 2003; Peace et al. 2011). Even an apparently simple installation such as a grab rail opens up a new set of relations between the user, the object and the building. To be exploited effectively, they depend on the user developing a new set of bodily practices to become enskilled in the use of the grab rail (Mauss 1973[1934]), contrary to the supposition that a grab rail is unproblematic and immediately useful (Seton and Bridge 2006). At present, the assumption in specifying and installing adaptations like a grab rail is that they prolong the ability of the user to carry out existing practices and routines, when in fact they act to force the user to continually alter their actions and daily routines and to develop new ways of living and new coping strategies. As Peace et al. (2011) describe, the capacity for the patient to 'fit' with their environment relies on a

\footnotetext{
${ }^{14}$ Further details are available at www.lifetimehomes.org.uk (accessed October 2014)

${ }^{15}$ Other forms of assistive technology based on ICT could be seen as more flexible, but suffer with the inflexibility of their infrastructure (Barlow et al. 2007).
} 
shifting boundary between what the adaptation allows them to do, and their ability to continually alter their behaviour. The surgery patients described by Kim et al. (2010) and the consequent need for them to alter their relationship with their domestic furniture is a good example of this at play. Any flexibility in the system resides with the user and not with the adaptive objects or their site of installation. If the reason for adaptations to be 'not needed' is due to this imbalance, then by delegating greater responsibility for flexibility to the objects and the home, we would expect increased longevity and more widespread applicability to any set of adaptations.

\section{Conclusions / Recommendations}

Demographic changes and economic imperatives are driving the need for more and better healthcare in the home. As a key component of that service, home adaptations for the disabled need to be effectively and sensitively implemented to create the best possible environment for the delivery of home-based care. Through the analysis of secondary data we have been able to highlight general themes, but there is a need for further research to corroborate, explain and attempt to resolve some of the issues raised here. Therefore we recommend the need for a methodologically diverse approach to be able to provide both larger-scale overviews and more detailed, household-level data. As a point of departure, we suggest an outline research agenda made up of three parts:

\section{Suitability of Adaptations}

The data show an increase in the provision of adaptations to the whole population of eligible households between 2003/4 and 2009/10, but also reveal a marked increase in the number of adaptations provided that are seen by the householders as unnecessary. The increase from $7 \%$ in EHCS2003 to 25\% in EHS2009 of un-needed adaptations is at present a phenomenon that has escaped investigation. Whilst there have been some efforts to push the Lifetime Homes agenda, including the introduction of new building regulations, that seems to us unlikely as a complete explanation for this increase. Recent government initiatives to promote healthcare at home (DoH 2010), changes to funding arrangements (DCLG 2008), and regional initiatives to restructure the process of specifying and installing adaptations (Ramsay 2010), seem more likely to have had a significant impact. Our suggestion is that there needs to be further research that seeks to explicitly understand the causes for this apparent phenomenon. This should include at least three key themes: a more detailed consideration of the links between regulatory frameworks that seek to promote the concept of lifetime homes, and the medical assessment and specification process (Hanson 2001); the potential for greater flexibility in the installation and longer term use of home adaptations (Rodden and Benford 2003); and a better understanding of need, taking greater account of the experience and requests of the householder even if these differ from prevailing medical recommendations (Gitlin 2009, Heywood 2004).

\section{Bias in Provision}

There are a series of questions posed by this research related to bias in provision, which can be inferred from our analysis, but there needs to be more detailed work to establish the size of the problem before we can understand the causes. Potential sources of bias include ethnic group, age and tenure, each with distinct underlying causes and requiring different approaches. We suggest that these three topics can and should be separately investigated further: First, culturally sensitive research, such as that conducted by Victor et al. (2012), needs to be extended to include attitudes towards adaptations, and to trace the routes through 
which different social groups express their needs and acquire their adaptations; Second, building on Imrie's recent research on Universal Design (2012), which removes age as the dominant definition of disability, we can better understand the provision of adaptations to other sectors of the disabled population, especially for example children; and third, our consideration of the links between tenure and access to home adaptations has been limited by the data, but does suggest an uneasy relationship between disabled living and home ownership (Williamson 2011), which deserves further research.

\section{Flexible Design}

Whether the explanation for the increase in 'unneeded' adaptations is due to the development of lifetime homes, or poorly-targeted provision following political and financial changes, it is clear that the adaptations themselves need to be more responsive to the changing needs of the users. This is equally important for growing children and fluctuating medical conditions, reflecting ongoing physical and social changes, and the move away from institutional healthcare. With the possible exception of some ICT-based home adaptations, there is very little flexibility in the material form of the objects or their potential spatial arrangements. Nor is there recognition of the home as a special and personal place, which carries with it different meanings and aesthetics to traditional healthcare institutions. We suggest that there needs to be an interdisciplinary research programme set up to adopt an innovative and artistic approach to assisted living. Disability adaptations could act as the forum for new design thinking about flexible devices, architecture and social arrangements that cope much better with the demands of long term occupation.

By highlighting some of the areas that need improvement or explanation, this paper is intended to act as a spur for further research. As political, medical and economic agendas converge on the benefits of delivering healthcare at home, this is likely to become of evergreater interest and importance to a wide range of audiences. In all of this clamour, the voice of the patient needs to be more clearly heard so that the changes currently envisaged can become part of a more sensitive and effective healthcare infrastructure.

\section{Acknowledgements}

This research was supported by funding from the Engineering and Physical Sciences Research Council (EPSRC) 'Health and Care Infrastructure Research and Innovation Centre' (HaCIRIC: EP/I029788/1). The authors also gratefully acknowledge the very helpful comments and advice given by the anonymous reviewers.

\section{References}

3 MillionLives. 2012. News Release: Minister welcomes 3millionlives approach, January 19 2012. http://3millionlives.co.uk//wp-content/uploads/2012/03/3millionlives-News-

Release.pdf. (Accessed Jan. 2013).

Adams, S. and Ellison, M. 2009. Time to adapt-Home adaptations for older people: The increase in need and future of state provision. Nottingham: Care and Repair England.

Angus, J., Kontos, P., Dyck, I., McKeever, P. and Poland, B. 2005. The personal significance of home: Habitus and the experience of receiving long-term home care. Sociology of Health and Illness 27(2): 161-187. 
Barlow, J., Bayer, S. and Curry, R. 2007. Flexible homes, flexible care, inflexible organisations? The role of telecare in supporting independence. Housing Studies 20(3): 441456.

Björnsdóttir, K. 2002. From the state to the family: Reconfiguring the responsibility for longterm nursing care at home. Nursing Enquiry 9(1): 3-11.

Bryman, A. 2012. Social Research Methods. Oxford: Oxford University Press.

Carroll, C., Cowans, J. and Darton, D (eds.). 1999. Meeting Part M and designing Lifetime Homes. York: Joseph Rowntree Foundation.

College of Occupational Therapists, Housing Corporation. 2006. Minor adaptations without delay. London: College of Occupational Therapists.

Department for Communities and Local Government. 2006. English House Condition Survey technical report (2003 edition): Decent homes and decent places. Wetherby: Communities and Local Government Publications.

Department for Communities and Local Government. 2008. Disabled Facilities Grant - The package of changes to modernise the programme. Wetherby: Communities and Local Government Publications.

Department of Health. 2010. Prioritising need in the context of 'Putting People First': A whole system approach to eligibility for social care. Guidance on eligibility criteria for adult social care, England 2010. Available on-line at: www.dh.gov.uk/en/Publicationsandstatistics/Publications/PublicationsPolicyAndGuidance/D H_113154 (Accessed Nov. 2012).

Dewsbury, G., Rouncefield, M., Clarke, K. and Sommerville, I. 2004. Depending on digital design: Extending inclusivity. Housing Studies 19(5): 811-825.

Ewart, I.J. and Luck, R. 2013. Living from home: Older people looking beyond the house. Home Cultures 10(1): 25-42.

Fänge, A. and Iwarsson, S. 2007. Challenges in the development of strategies for housing adaptation evaluations. Scandinavian Journal of Occupational Therapy 14: 140-149.

Gitlin, L. 2003. Conducting research on home environments: Lessons learned and new directions. The Gerontologist 43(5): 628-637.

Gitlin, L.N. 2009. Environmental adaptations for older adults and their families in the home and community. In Söderback, I. (ed.) International Handbook of occupational therapy interventions, pp. 53-62. New York: Springer.

Goldsmith, S. 1997. Designing for the disabled: A new paradigm. London: Architectural Press.

Ham, C., Dixon, A. and Brooke, B. 2012. Transforming the delivery of health and social care: The case for fundamental change. London: Kings Fund. 
Hanson, J. 2001. From sheltered housing to lifetime homes: an inclusive approach to housing. In Winters, S., (ed.) Lifetime Housing in Europe: Proceedings of the European seminar and colloquium "Living tomorrow starts today". Leuven: Katholieke Unversiteit Leuven. pp. 3557.

Harris, J. 2010. The use, role and application of advanced technology in the lives of disabled people in the UK. Disability and Society 25(4): 427-439.

Heywood, F. 2004. Understanding needs: A starting point for quality. Housing Studies 19(5): 709-726.

Heywood, F. 2005. Adaptation: Altering the house to restore the home. Housing Studies 20(4): 531-547.

Heywood, F. and Turner, L. 2007. Better outcomes, lower costs: Implications for health and social care budgets of investment in housing adaptations, improvements and equipment. Leeds: HMSO.

HM Government, 2010. The building regulations 2010. Access to and use of buildings. Approved document M (2004 edition incorporating 2010 amendments). Available online at: http://www.planningportal.gov.uk/uploads/br/BR_PDF_ADM_2004.pdf (Accessed Dec. 2012).

Hoffmann, T. and McKenna, K. 2004. A survey of assistive equipment use by older people following hospital discharge. British Journal of Occupational Therapy 67(2): 75-82.

Imrie, R. 2004a. Disability, embodiment and the meaning of home. Housing Studies 19(5): 745-763.

Imrie, R. 2004b. The role of the building regulations in achieving housing quality. Environment and Planning B: Planning and Design 31(3): 419-437.

Imrie, R. 2012. Universalism, universal design and equitable access to the built environment, Disability and Rehabilitation 34(10): 873-882.

Johansson, K., Josephsson, S. and Lilja, M. 2009. Creating possibilities for action in the presence of environmental barriers in the process of 'ageing in place'. Ageing and Society 29: 49-70.

Katbamna, S., Ahmad, W., Bhakta, P., Baker, R. And Parker, G. 2004. Do they look after their own? Informal support for South Asian carers. Health and Social Care in the Community 12(5): 398-406.

Kim, T.K., Kwon, S.K., Kang, Y.G., Chang, C.B. and Seong, S.C. 2010. Functional disabilities and satisfaction after total knee arthroplasty in female Asian patients. The Journal of Arthroplasty 25(3): 458-464.

Mann, W.C., Goodall, S., Justiss, M.D. and Tomita, M. 2002. Dissatisfaction and nonuse of assistive devices among frail elders. Assistive Technology 14(2): 130-139. 
Manzo, L.C. 2003. Beyond house and haven: Towards a revisioning of emotional relationships with places. Journal of Environmental Psychology 23(1): 47-61.

Mauss, M. 1973. Techniques of the body. Economy and Society 2(1): 70-88. [Originally published in French 1934]

McCreadie, C. and Tinker, A. 2005. The acceptability of assistive technology to older people. Ageing and Society 25: 91-110.

Niva, B and Skar, L. 2006. A pilot study of the activity patterns of five elderly persons after a housing adaptation. Occupational Therapy International 13(1): 21-34.

Office for National Statistics. 2013. A Century of Home Ownership and Renting in England and Wales (full story). Part of 2011 Census Analysis. Available at:

http://www.ons.gov.uk/ons/rel/census/2011-census-analysis/a-century-of-home-ownershipand-renting-in-england-and-wales/short-story-on-housing.html (Accessed Feb. 2014).

Oswald, F. and Wahl H.-W. 2005. Dimensions of the meaning of home. In Rowles, G.D. and Chaudhury, H. (eds.) Home and Identity in Later Life: International Perspectives. New York: Springer. pp. 21-45.

Peace, S., Holland, C. and Kellaher, L. 2011. 'Option recogniton' in later life: Variations in ageing in place. Ageing \& Society 31: 734-757.

Ramsay, M. 2010. Adapting for a lifetime: The key role of home improvement agencies in adaptations delivery. Glossop: Foundations.

Rodden, T. and Benford, S. 2003. The evolution of buildings and implications for the design of ubiquitous domestic environments. Proceedings of the 2003 CHI conference: New Horizons. April 5-10, Ft. Lauderdale, Florida. pp. 9-16.

Seton, H. and Bridge, C. 2006. Standing up: A systematic review of grabrail orientations. In Mann, W. C. and Helal, A. (eds.) Promoting independence for older persons with disabilities. Amsterdam: IOS Press. pp. 169-188.

Steventon, A., Bardsley, M., Billings, J., Dixon, J., Doll, H., Hirani, S., Cartwright, M., Rixon, L., Knapp, M., Henderson, C., Rogers, A., Fitzpatrick, R., Hendy, J. and Newman, S. 2012. Effect of telehealth on use of secondary care and mortality: findings from the Whole System Demonstrator cluster randomized trial, British Medical Journal 344: e3874.

Victor, C., Martin, W. and Zubair, M. 2012. Families and caring in South Asian Communities: a pilot study. European Journal of Social Work 15(1): 81-96.

Williamson, N. 2011. Supporting people in private rented sector housing. Glossop: Foundations. 